\title{
Anti-Müllerian hormone and polycystic ovary syndrome
}

\author{
Agnieszka Łebkowska, Irina Kowalska \\ Department of Endocrinology, Diabetology, and Internal Medicine, Medical University of Bialystok, Poland
}

\begin{abstract}
Anti-Müllerian hormone (AMH) is a glycoprotein, a member of the transforming growth factor $\beta$ family, reflecting the number of ovarian antral follicles. Polycystic ovary syndrome (PCOS) is a common endocrinopathy predisposing to infertility, and metabolic and cardiovascular complications. In our review, we discuss the role of AMH in PCOS pathophysiology and its clinical applications according to the published studies. Improvement of AMH assay validity will allow the clinical utility of this valuable biomarker to be widened. (Endokrynol Pol 2017; 68 (1): 74-78)
\end{abstract}

Key words: AMH; PCOS; polycystic ovarian morphology; insulin resistance; assisted reproductive technology

\section{Introduction}

Anti-Müllerian hormone (AMH) is a dimeric glycoprotein and a member of the transforming growth factor $\beta$ family (TGF $\beta$ ). AMH is a well-recognised biomarker of ovarian reserve. Polycystic ovary syndrome (PCOS) is the most common endocrine disorder among women of reproductive age with a prevalence between 6 and 10\% based on the U.S. National Institutes of Health (NIH) criteria, and reaching approximately $20 \%$ according to the Rotterdam criteria [1]. Serum AMH concentration is higher in women with PCOS and correlates with the number of 2-6 $\mathrm{mm}$ antral follicles observed by transvaginal ultrasound of the ovaries [2,3]. It has been proposed as a more sensitive and specific marker of antral follicle count (AFC) than ultrasound [4]. Additionally, serum AMH concentration is related to severity of hyperandrogenism and oligo-anovulation in PCOS [5].

\section{AMH-physiology}

In the male foetus, the Sertoli cells in developing testes produce $\mathrm{AMH}$, which through AMH receptortype II (AMHR-II) activation induces regression of the paramesonephric ducts. Strong AMH expression is involved in testicular differentiation during foetal development up to puberty [6]. In the female foetus, the absence of $\mathrm{AMH}$ results in the development of the paramesonephric ducts into the oviduct, uterus, and the upper $2 / 3$ of the vagina. Production of AMH starts from about the $36^{\text {th }}$ week of gestation and lasts until menopause [7].
AMH is mainly expressed in granulosa cells of growing antral and pre-antral follicles in the gonadotropinindependent phase. Serum AMH reflects the secretion of AMH only from the follicles that are vascularised [8]. AMH regulates follicle growth by the inhibition of their sensitivity to follicle-stimulating hormone ( $\mathrm{FSH}$ ) [9]. In the physiological menstrual cycle, when the follicle matures and reaches a diameter of around $6 \mathrm{~mm}$, it enters the FSH-dependent growth phase, resulting in follicle selection and ovulation. It should be highlighted that selection of the follicle is based on its own sensitivity to $\mathrm{FSH}$, and it requires FSH to continue its growth. After that time, there is a gradual reduction of intrafollicular AMH concentration. Oocyte, depending on the stage in preantral, antral, and preovulatory follicles, can regulate AMH expression in granulosa cells $[10,11]$. Additionally, elevated oestrogen production and FSH can downregulate AMH activity [12].

Recently Gnoth et al. confirmed that AMH concentrations decrease in periovulatory time, when a follicle reaches $7 \mathrm{~mm}$ diameter, which was observed in high-resolution ultrasound [13]. An inverse association between intra-follicular concentrations of $\mathrm{AMH}$, estradiol concentrations, and aromatase CYP19a1 gene expression in human antral follicles has been confirmed [14, 15]. In the absence of AMH, as presented in AMH-null mice, primordial follicles are still recruited, resulting in a decline of the follicle pool [16]. This suggests that AMH is involved in the regulation of follicular recruitment and the threshold for FSH sensitivity. 


\section{Clinical implications}

Concerning AMH levels during a woman's life, there is a peak shortly after birth and at an age of around 25 years. After that, a steady decline to undetectable levels at an average age of 50-51 years is observed [17]. A positive relationship between $\mathrm{AMH}$ and $\mathrm{AFC}$ has been demonstrated in a large number of studies, which indirectly reflects ovarian reserve. Variability in the number of antral follicles may result in AMH level differences [18-21]. Recent studies indicate that AMH concentration may vary according to the ethnicity, with lower serum AMH level in African-American and Hispanic women in comparison to Caucasian women [22, 23]. Through the menstrual cycle, AMH concentration seems to be relatively stable, although a slight increase is observed during the follicular phase of the regular menstrual cycle in women of age over 30 years [24]. Conditions such as oral contraceptive use or pregnancy, however, cause a decrease in serum AMH level [25, 26].

In clinical practice, AMH can predict the ovarian response to stimulation and is useful in assessment of the quantitative aspects of the ovarian reserve [27]. It can also serve as a tool for investigation of gonadotoxicity of cancer therapy and loss of ovarian reserve from ovarian surgery [28]. In recent studies AMH has also been presented as a predictor of fertility and menopause time. Women with lower age-specific AMH level will have menopause earlier [29]. Using age and AMH, the age range in which menopause will subsequently occur can even be individually calculated [30]. It should be highlighted that women with type 1 diabetes (T1DM) experience menopause at a younger age, even eight years earlier compared to their sisters [31]. Soto et al. observed lower AMH concentrations in women with T1DM in their fourth decade of life, suggesting a decline in ovarian follicle pool and premature aging of ovaries [32]. Nevertheless, the number of genetic regions and variants are studied in pathways of menopausal timing [33].

\section{$\mathrm{AMH}$ in PCOS}

PCOS is a complex endocrine disorder with three main signs and symptoms including menstrual irregularity — oligomenorrhoea/amenorrhoea (OM), biochemical or clinical hyperandrogenism, hirsutism, acne, alopecia (HA), and polycystic ovarian morphology (PCOM). According to Rotterdam criteria, there are four phenotypes of PCOS: I classic phenotype with all three criteria fulfilled, II phenotype with HA and OM, III phenotype with HA and PCOM, and IV phenotype with OM and PCOM [34]. The pathogenesis of the disease is multifactorial, combining genetic predispositions with environmental influence [35]. Women with PCOS are considered as a group with high risk of obesity, insulin resistance, metabolic syndrome, type 2 diabetes, fertility disorders, and cardiovascular diseases [1,36].

Serum AMH in women with PCOS is higher than in healthy women. It probably reflects the number of small follicles observed in ultrasound of polycystic ovaries. Moreover, it has been demonstrated that AMH production per granulosa cell was 75 -fold higher in anovulatory PCOS women, and 20-fold higher in ovulatory PCOS women, than in healthy controls $[37,38]$. This observation was confirmed in a study on follicular fluid in the PCOS group [39]. The causes of such high levels of AMH are still unknown. High amounts of androgens seem to be an intrinsic defect of theca cells from polycystic ovaries [40]. It has also been indicated that hyperandrogenism stimulates preantral and antral follicular growth in the ovary, resulting in AMH elevation [41]. To confirm this, Cassar et al. have indicated testosterone as the only independent predictor of AMH overall in women with PCOS [42]. Additionally, LH reduces AMHR-II expression in granulosa cells in women with normal ovaries and ovulatory PCOS, but does not have this effect in anovulatory PCOS women [43]. These mechanisms suggest an important role of AMH in ovulatory dysregulation.

\section{AMH and PCOS phenotypes}

AMH serum levels seem to be related to severity of PCOS - women with classic phenotype have the highest serum AMH levels [5, 44]. Supporting these findings, Tal et al. reported that $97 \%$ of women with $\mathrm{AMH}>10 \mathrm{ng} / \mathrm{mL}$ presented PCOS and that AMH correlated positively with $\mathrm{LH}$, total testosterone, and dehydroepiandrosterone sulphate. Additionally, AMH showed high predictive ability for the presence of menstrual disorders [45]. Recently published papers revealed intrinsic granulosa cells dysregulation, indicating the AMH/AFC ratio as being more closely related to the menstrual status than the AMH level by itself. The AMH/AFC ratio was significantly higher in oligoamenorrhoeic women with PCOS than in those with regular menstruation [46].

\section{$A M H$ and its relation to obesity and insulin resistance in PCOS}

There are contradictory results concerning the association of AMH and obesity in women with PCOS. Recently, Olszanecka-Glinianowicz et al. reported that AMH levels were lower in obese women with PCOS than in normal weight PCOS women [47]. Conversely, Cassar et al. found no differences in AMH levels between lean and obese women with PCOS [42]. In previously published studies, it has been proposed that insulin resistance, related to obesity, influences the function 
of granulosa cells and decreases AMH production [48]. Furthermore, obesity could have an inhibitory effect on gonadotropin release, suppressing LH and follicle development, leading to elevated AMH concentrations [49]. Taking into account that PCOS women are commonly insulin resistant, the association between AMH and insulin resistance (IR) has been studied. Indirect measurements of IR have been associated with AMH either positively or negatively, or no association has been found [37, 47, 50]. Cassar et al., assessing IR by euglycaemic-hyperinsulinaemic clamp, did not find direct relationship between AMH and IR. However, IR influences androgen production, regulating AMH over-secretion [42].

\section{AMH in PCOS diagnosis}

The strong involvement of AMH in the pathophysiology of PCOS has opened a wide discussion about whether AMH could be involved in facilitating the diagnosis of PCOS. Increased serum AMH level of $>35 \mathrm{pmol} / \mathrm{L}$ (or $>5 \mathrm{ng} / \mathrm{mL}$ ) has been proposed for the definition of PCOM in the diagnosis of PCOS, as a more sensitive and specific marker than follicle count in ultrasonographic examination [4]. With the latest generation of ultrasound equipment, it has been proposed that the threshold of follicle count be increased from 12 (established in 2003 by Rotterdam criteria) to 19 or 25 follicles [4, 51]. Lauritsen et al. observed that replacing the criterion for polycystic ovaries above 19 antral follicles or AMH $>35 \mathrm{pmol} / \mathrm{L}$ resulted in a PCOS prevalence of 6.3 and $8.5 \%$, respectively, and this was significantly lower in comparison to prevalence of $16.6 \%$ according to the standard Rotterdam criteria [52]. Additionally, it has been shown that for the diagnosis of PCOS the combination of OM and/or HA with AMH shows $83 \%$ sensitivity and $100 \%$ specificity according to the Rotterdam criteria [53].

Due to the fact that published studies use different assays, the values of serum AMH obtained in one assay may not be directly translated to the other. Until 2010, serum AMH concentrations were measured using first-generation commercial AMH ELISAs developed by two independent laboratories: Diagnostic System Laboratories (DSL) and Immunotech (IOT). These assays have subsequently been replaced by second-generation methods - Beckman Coulter Gen II [54]. In 2013, the modified protocol for second-generation assay for AMH was released (Gen IIm). It included a predilution step of the specimen in assay buffer before addition to the ELISA plate, which gave more reliable AMH results [55]. Currently, fully automatic measurements of serum AMH concentrations are also available (Elecsys, $\mathrm{AMH}$, Roche and Access, AMH, Beckman Coulter) [56]. Moreover, new commercial AMH enzyme-linked immunosorb- ent assay (picoAMH ELISA, AnshLabs) with a lower threshold of detection is useful especially in women with diminished ovarian reserve [57]. Therefore, it is impossible to set the international diagnostic threshold for serum AMH. Androgen Excess Society Task Force recommends against considering an increased serum AMH concentration as a surrogate marker of PCOM until the standardisation of AMH assay becomes available [54].

\section{AMH in assisted reproductive technology}

In human assisted reproductive technology, exogenous FSH therapy should provide a satisfactory answer without complications such as inadequate response or ovarian hyperstimulation syndrome. There are several parameters used as predictors of ovarian response to stimulation - ultrasound variables, $\mathrm{FSH}$, inhibin $\mathrm{B}$, $17-\beta$-estradiol, and AMH. Hormonal variability between menstrual cycles hinders reliable assessment [58]. Seifer et al. first described AMH concentrations corresponding to a number of oocytes retrieved and mature oocytes in infertile women [59]. It has been shown that AMH is a good predictor of high and low ovarian response during ovarian stimulation $[27,60]$. New ultrasensitive method of measurement of AMH - picoAMH immunoassay - allows estimation of very low AMH concentrations [57].

\section{Conclusions}

$\mathrm{AMH}$ is a very promising biomarker of ovarian function in a large array of clinical applications. PCOS has reproductive, metabolic, and psychological features, and it is the most common cause of anovulatory infertility. $\mathrm{AMH}$ is an invaluable tool offering insight into ovarian function and assessment of treatment, especially in women with PCOS.

\section{Acknowledgments}

We are grateful to Prof. Sławomir Wołczyński (Department of Reproduction and Gynaecological Endocrinology, Medical University of Białystok) for critical comments and remarks.

\section{References}

1. Fauser BC, Tarlatzis BC, Rebar RW, et al. Consensus on women's health aspects of polycystic ovary syndrome (PCOS): the Amsterdam ESHRE/ ASRM-Sponsored 3rd PCOS Consensus Workshop Group. Fertil Steril. 2012; 97(1): 28-38.e25, doi: 10.1016/j.fertnstert.2011.09.024, indexed in Pubmed: 22153789.

2. Pigny P,Merlen E, Robert Y, et al. Elevated serum level of anti-mullerian hormone in patients with polycystic ovary syndrome: relationship to the ovarian follicle excess and to the follicular arrest. J Clin Endocrinol Metab. 2003; 88(12): 5957-5962, doi: 10.1210/jc.2003-030727, indexed in Pubmed: 14671196.

3. Pigny $P$, Jonard S, Robert Y, et al. Serum anti-Mullerian hormone as a surrogate for antral follicle count for definition of the polycystic ovary syndrome. J Clin Endocrinol Metab. 2006; 91(3): 941-945, doi: 10.1210/jc.2005-2076, indexed in Pubmed: $\underline{16368745}$. 
4. Dewailly D, Gronier H, Poncelet E, et al. Diagnosis of polycystic ovary syndrome (PCOS): revisiting the threshold values of follicle count on ultrasound and of the serum AMH level for the definition of polycystic ovaries. Hum Reprod. 2011; 26(11): 3123-3129, doi: 10.1093/humrep/der297, indexed in Pubmed: 21926054

5. Piouka A, Farmakiotis D, Katsikis I, et al. Anti-Mullerian hormone levels reflect severity of PCOS but are negatively influenced by obesity: relationship with increased luteinizing hormone levels. Am J Physiol Endocrinol Metab. 2009; 296(2): E238-E243, doi: 10.1152/ajpendo.90684.2008, indexed in Pubmed: 18957615.

6. Rey RA, Grinspon RP, Gottlieb S, et al. Male hypogonadism: an extended classification based on a developmental, endocrine physiology-based approach. Andrology. 2013; 1(1): 3-16, doi: 10.1111/j.2047-2927.2012.00008.x, indexed in Pubmed: 23258624.

7. La Marca A, Volpe A. Anti-Müllerian hormone (AMH) in female reproduction: is measurement of circulating AMH a useful tool? Clin Endocrinol (Oxf). 2006; 64(6): 603-610, doi: 10.1111/j.1365-2265.2006.02533.x, indexed in Pubmed: 16712660.

8. Dewailly D, Andersen CY, Balen A, et al. The physiology and clinical utility of anti-Mullerian hormone in women. Hum Reprod Update. 2014; 20(3): 370-385, doi: 10.1093/humupd/dmt062, indexed in Pubmed: 24430863.

9. Pellatt L, Rice S, Dilaver N, et al. Anti-Müllerian hormone reduces follicle sensitivity to follicle-stimulating hormone in human granulosa cells. Fertil Steril. 2011; 96(5): 1246-12451.e1, doi: 10.1016/j.fertnstert.2011.08.015, indexed in Pubmed: 21917251.

10. Andersen CY, Schmidt KT, Kristensen SG, et al. Concentrations of AMH and inhibin-B in relation to follicular diameter in normal human small antral follicles. Hum Reprod. 2010; 25(5): 1282-1287, doi: 10.1093/humrep/deq019, indexed in Pubmed: 20228388.

11. Peluso C, Fonseca FLA, Rodart IF, et al. AMH: An ovarian reserve biomarker in assisted reproduction. Clin Chim Acta. 2014; 437: 175-182, doi: 10.1016/j. cca.2014.07.029, indexed in Pubmed: 25086280.

12. Grynberg M, Pierre A, Rey R, et al. Differential regulation of ovarian antimüllerian hormone $(\mathrm{AMH})$ by estradiol through $\alpha$ - and $\beta$-estrogen receptors.J Clin Endocrinol Metab. 2012; 97(9): E1649-E1657, doi: 10.1210/jc.2011-3133, indexed in Pubmed: 22689696.

13. Gnoth C, Roos J, Broomhead D, et al. Antimüllerian hormone levels and numbers and sizes of antral follicles in regularly menstruating women of reproductive age referenced to true ovulation day. Fertil Steril. 2015; 104(6): 1535-15343.e1, doi: 10.1016/j.fertnstert.2015.08.027, indexed in Pubmed: 26384163.

14. Nielsen ME, Rasmussen IA, Kristensen SG, et al. In human granulosa cells from small antral follicles, androgen receptor mRNA and androgen levels in follicular fluid correlate with FSH receptor mRNA. Mol Hum Reprod. 2011; 17(1): 63-70, doi: 10.1093/molehr/gaq073, indexed in Pubmed: 20843821.

15. Andersen CY, Byskov AG. Estradiol and regulation of anti-Müllerian hormone, inhibin-A, and inhibin-B secretion: analysis of small antral and preovulatory human follicles' fluid. J Clin Endocrinol Metab. 2006; 91(10): 4064-4069, doi: $10.1210 / \mathrm{jc} .2006-1066$, indexed in Pubmed: 16895952.

16. Visser JA, Durlinger ALL, Peters IJJ, et al. Increased oocyte degeneration and follicular atresia during the estrous cycle in anti-Müllerian hormone null mice. Endocrinology. 2007; 148(5): 2301-2308, doi: 10.1210/en.2006-1265, indexed in Pubmed: 17255205.

17. Kelsey TW, Wright $\mathrm{P}$, Nelson SM, et al. A validated model of serum antimüllerian hormone from conception to menopause. PLoS One. 2011; 6(7): e22024, doi: 10.1371/journal.pone.0022024, indexed in Pubmed: 21789206.

18. La Marca A, Spada E, Sighinolfi G, et al. Age-specific nomogram for the decline in antral follicle count throughout the reproductive period. Fertil Steril. 2011; 95(2): 684-688, doi: 10.1016/j.fertnstert.2010.07.1069, indexed in Pubmed: 20797717.

19. Fanchin R, Schonäuer LM, Righini C, et al. Serum anti-Müllerian hormone is more strongly related to ovarian follicular status than serum inhibin B, estradiol, FSH and LH on day 3. Hum Reprod. 2003; 18(2): 323-327, indexed in Pubmed: 12571168

20. Broekmans FJM, de Ziegler D, Howles CM, et al. The antral follicle count: practical recommendations for better standardization. Fertil Steril. 2010; 94(3): 1044-1051, doi: 10.1016/i.fertnstert.2009.04.040, indexed in Pubmed: 19589513.

21. Jeppesen JV, Anderson RA, Kelsey TW, et al. Which follicles make the most anti-Mullerian hormone in humans? Evidence for an abrupt decline in AMH production at the time of follicle selection. Mol Hum Reprod. 2013; 19(8): 519-527, doi: 10.1093/molehr/gat024, indexed in Pubmed: 23562944.

22. Seifer DB, Golub ET, Lambert-Messerlian G, et al. Variations in serum müllerian inhibiting substance between white, black, and Hispanic women. Fertil Steril. 2009; 92(5): 1674-1678, doi: 10.1016/j.fertnstert.2008.08.110, indexed in Pubmed: 18930217.

23. Schuh-Huerta SM, Johnson NA, Rosen MP, et al. Genetic variants and environmental factors associated with hormonal markers of ovarian reserve in Caucasian and African American women. Hum Reprod. 2012; 27(2): 594-608, doi: 10.1093/humrep/der391, indexed in Pubmed: 22116950.
24. Lambert-Messerlian G, Plante B, Eklund EE et al. Levels of antimüllerian hormone in serum during the normal menstrual cycle. Fertil Steril. 2016; 105(1): 208-213.e1, doi: 10.1016/j.fertnstert.2015.09.033, indexed in Pubmed: 26477497.

25. Bentzen JG, Forman JL, Pinborg A, et al. Ovarian reserve parameters: a comparison between users and non-users of hormonal contraception. Reprod Biomed Online. 2012; 25(6): 612-619, doi: 10.1016/i. rbmo.2012.09.001, indexed in Pubmed: 23069740.

26. Nelson SM, Stewart F, Fleming R, et al. Longitudinal assessment of antimüllerian hormone during pregnancy-relationship with maternal adiposity, insulin, and adiponectin. Fertil Steril. 2010; 93(4): 1356-1358, doi: 10.1016/j.fertnstert.2009.07.1676, indexed in Pubmed: 19800062

27. Broer SL, van Disseldorp J, Broeze KA, et al. IMPORT study group. Added value of ovarian reserve testing on patient characteristics in the prediction of ovarian response and ongoing pregnancy: an individual patient data approach. Hum Reprod Update. 2013; 19(1): 26-36, doi: 10.1093/humupd/dms041, indexed in Pubmed: 23188168.

28. Partridge AH, Ruddy KJ, Gelber S, et al. Ovarian reserve in women who remain premenopausal after chemotherapy for early stage breast cancer. Fertil Steril. 2010; 94(2): 638-644, doi: 10.1016/j.fertnstert.2009.03.045, indexed in Pubmed: 19409543.

29. Tehrani FR, Solaymani-Dodaran M, Azizi F. A single test of antimullerian hormone in late reproductive-aged women is a good predictor of menopause. Menopause. 2009; 16(4): 797-802, doi: 10.1097 gme.0b013e318193e95d, indexed in Pubmed: 19225427.

30. Broer SL, Eijkemans MJC, Scheffer GJ, et al. Anti-mullerian hormone predicts menopause: a long-term follow-up study in normoovulatory women. J Clin Endocrinol Metab. 2011; 96(8): 2532-2539, doi: 10.1210 ic. 2010-2776, indexed in Pubmed: 21613357.

31. Dorman JS, Steenkiste AR, Foley TP, et al. Familial Autoimmune and Diabetes (FAD) Study. Menopause in type 1 diabetic women: is it premature? Diabetes. 2001; 50(8): 1857-1862, indexed in Pubmed: $\underline{11473049}$

32. Soto N, Iñiguez G, López P, et al. Anti-Mullerian hormone and inhibin $\mathrm{B}$ levels as markers of premature ovarian aging and transition to menopause in type 1 diabetes mellitus. Hum Reprod. 2009; 24(11): 2838-2844, doi: 10.1093/humrep/dep276, indexed in Pubmed: 19643804.

33. Voorhuis M, Onland-Moret NC, van der Schouw YT, et al. Human studies on genetics of the age at natural menopause: a systematic review. Hum Reprod Update. 2010; 16(4): 364-377, doi: 10.1093/humupd/dmp055, indexed in Pubmed: 20071357.

34. Rotterdam ESHRE/ASRM-Sponsored PCOS Consensus Workshop Group, Rotterdam ESHRE/ASRM-Sponsored PCOS consensus workshop group. Revised 2003 consensus on diagnostic criteria and long-term health risks related to polycystic ovary syndrome (PCOS). Hum Reprod. 2004; 19(1): 41-47, indexed in Pubmed: 14688154.

35. McAllister JM, Legro RS, Modi BP, et al. Functional genomics of PCOS from GWAS to molecular mechanisms. Trends Endocrinol Metab. 2015; 26(3): 118-124, doi: 10.1016/j.tem.2014.12.004, indexed in Pubmed: 25600292.

36. Foltyn W, Strzelczyk J, Marek B, et al. Selected markers of endothelia dysfunction in women with polycystic ovary syndrome. Endokrynol Pol. 2011; 62(3): 243-248, indexed in Pubmed: 21717407.

37. Park AS, Lawson MA, Chuan SS, et al. Serum anti-mullerian hormone concentrations are elevated in oligomenorrheic girls without evidence of hyperandrogenism. J Clin Endocrinol Metab. 2010; 95(4): 1786-1792, doi: 10.1210/jc.2009-2106, indexed in Pubmed: 20150576.

38. Pellatt L, Hanna L, Brincat M, et al. Granulosa cell production of antiMüllerian hormone is increased in polycystic ovaries. J Clin Endocrinol Metab. 2007; 92(1): 240-245, doi: 10.1210/jc.2006-1582, indexed in Pubmed: 17062765

39. Das M, Gillott DJ, Saridogan E, et al. Anti-Mullerian hormone is increased in follicular fluid from unstimulated ovaries in women with polycystic ovary syndrome. Hum Reprod. 2008; 23(9): 2122-2126, doi: 10.1093 humrep/den185, indexed in Pubmed: 18550512.

40. Gilling-Smith C, Willis DS, Beard RW, et al. Hypersecretion of androstenedione by isolated thecal cells from polycystic ovaries. J Clin Endocrino Metab. 1994; 79(4): 1158-1165, doi: 10.1210/jcem.79.4.7962289, indexed in Pubmed: 7962289.

41. Diamanti-Kandarakis E, Christakou CD, Kandaraki E, et al. Polycystic ovarian syndrome: pathophysiology, molecular aspects and clinical implications. Expert Rev Mol Med. 2008; 10(2): e3-212, doi: 10.1017/ S1462399408000598, indexed in Pubmed: 18230193.

42. Cassar S, Teede HJ, Moran LJ, et al. Polycystic ovary syndrome and antiMüllerian hormone: role of insulin resistance, androgens, obesity and gonadotrophins. Clin Endocrinol (Oxf). 2014; 81(6): 899-906, doi: 10.1111/ cen.12557, indexed in Pubmed: 25040369.

43. Pierre A, Peigné M, Grynberg M, et al. Loss of LH-induced down-regulation of anti-Müllerian hormone receptor expression may contribute to anovulation in women with polycystic ovary syndrome. Hum Reprod. 2013; 28(3): 762-769, doi: 10.1093/humrep/des460, indexed in Pubmed: 23321213. 
44. Sahmay S, Atakul N, Oncul M, et al. Serum anti-Mullerian hormone levels in the main phenotypes of polycystic ovary syndrome. Eur J Obstet Gynecol Reprod Biol. 2013; 170(1): 157-161, doi: 10.1016/j. ejogrb.2013.05.019, indexed in Pubmed: 23806449.

45. Tal R, Seifer DB, Khanimov M, et al. Characterization of women with elevated antimüllerian hormone levels (AMH): correlation of AMH with polycystic ovarian syndrome phenotypes and assisted reproductive technology outcomes. Am J Obstet Gynecol. 2014; 211(1): 59.e1-59.e8, doi: 10.1016/j.ajog.2014.02.026, indexed in Pubmed: 24593938.

46. Alebić MŠ, Stojanović N, Duhamel A, et al. The phenotypic diversity in per-follicle anti-Müllerian hormone production in polycystic ovary syndrome. Hum Reprod. 2015; 30(8): 1927-1933, doi: 10.1093/humrep/ dev131, indexed in Pubmed: 26048913.

47. Olszanecka-Glinianowicz M, Madej P, Owczarek A, et al. Circulating anti-Müllerian hormone levels in relation to nutritional status and selected adipokines levels in polycystic ovary syndrome. Clin Endocrinol (Oxf). 2015; 83(1): 98-104, doi: 10.1111/cen.12687, indexed in Pubmed: 25440474.

48. Chen MJ, Yang WS, Chen CL, et al. The relationship between anti-Mullerian hormone, androgen and insulin resistance on the number of antral follicles in women with polycystic ovary syndrome. Hum Reprod. 2008; 23(4): 952-957, doi: 10.1093/humrep/den015, indexed in Pubmed: 18256110.

49. Grossman MP, Nakajima ST, Fallat ME, et al. Müllerian-inhibiting substance inhibits cytochrome $\mathrm{P} 450$ aromatase activity in human granulosa lutein cell culture. Fertil Steril. 2008; 89(5 Suppl): 1364-1370, doi: 10.1016/j. fertnstert.2007.03.066, indexed in Pubmed: 17517397.

50. Skałba P, Cygal A, Madej P, et al. Is the plasma anti-Müllerian hormone (AMH) level associated with body weight and metabolic, and hormonal disturbances in women with and without polycystic ovary syndrome? Eur J Obstet Gynecol Reprod Biol. 2011; 158(2): 254-259, doi: 10.1016/j. ejogrb.2011.06.006, indexed in Pubmed: 21752527.

51. Lujan ME, Jarrett BY, Brooks ED, et al. Updated ultrasound criteria for polycystic ovary syndrome: reliable thresholds for elevated follicle population and ovarian volume. Hum Reprod. 2013; 28(5): 1361-1368, doi: 10.1093/humrep/det062, indexed in Pubmed: 23503943.

52. Lauritsen MP, Bentzen JG, Pinborg A, et al. The prevalence of polycystic ovary syndrome in a normal population according to the Rotterdam criteria versus revised criteria including anti-Mullerian hormone. Hum
Reprod. 2014; 29(4): 791-801, doi: 10.1093/humrep/det469, indexed in Pubmed: 24435776

53. Sahmay S, Aydin Y, Oncul M, et al. Diagnosis of Polycystic Ovary Syndrome: AMH in combination with clinical symptoms. J Assist Reprod Genet. 2014; 31(2): 213-220, doi: 10.1007/s10815-013-0149-0, indexed in Pubmed: 24343036.

54. Dewailly D, Lujan ME, Carmina $\mathrm{E}$, et al. Definition and significance of polycystic ovarian morphology: a task force report from the Androgen Excess and Polycystic Ovary Syndrome Society. Hum Reprod Update. 2014; 20(3): 334-352, doi: 10.1093/humupd/dmt061, indexed in Pubmed: 24345633

55. Craciunas L, Roberts SA, Yates AP, et al. Modification of the BeckmanCoulter second-generation enzyme-linked immunosorbent assay protocol improves the reliability of serum antimüllerian hormone measurement. Fertil Steril. 2015; 103(2): 554-59.e1, doi: 10.1016/j.fertnstert.2014.10.052, indexed in Pubmed: 25487749.

56. Nelson SM, Pastuszek E, Kloss G, et al. Two new automated, compared with two enzyme-linked immunosorbent, antimüllerian hormone assays. Fertil Steril. 2015; 104(4): 1016-1021.e6, doi: 10.1016/j.fertnstert.2015.06.024, indexed in Pubmed: 26183313.

57. Burks HR, Ross L, Opper N, et al. Can highly sensitive antimüllerian hormone testing predict failed response to ovarian stimulation? Fertil Steril. 2015; 104(3): 643-648, doi: 10.1016/j.fertnstert.2015.06.018, indexed in Pubmed: 26158904

58. Broekmans FJ, Kwee J, Hendriks DJ, et al. A systematic review of test predicting ovarian reserve and IVF outcome. Hum Reprod Update. 2006; 12(6): 685-718, doi: 10.1093/humupd/dml034 indexed in Pubmed: 16891297.

59. Seifer DB, MacLaughlin DT, Christian BP, et al. Early follicular serum müllerian-inhibiting substance levels are associated with ovarian response during assisted reproductive technology cycles. Fertil Steril. 2002; 77(3): 468-471, indexed in Pubmed: 11872196.

60. Broer SL, Dólleman M, van Disseldorp J et al. Prediction of an excessive response in in vitro fertilization from patient characteristics and ovarian reserve tests and comparison in subgroups: an individual patient data meta-analysis. Fertil Steril 2013; 100: 420-429.e7. doi: 10.1016/j. fertnstert.2013.04.024 


\title{
Hormon anty-müllerowski i zespół policystycznych jajników
}

\author{
Agnieszka Łebkowska, Irina Kowalska \\ Klinika Endokrynologii, Diabetologii i Chorób Wewnętrznych, Uniwersytet Medyczny, Białystok, Polska
}

Artykuł jest tłumaczeniem pracy: Łebkowska A, Kowalska I. Anti-Müllerian hormone and polycystic ovary syndrome. Endokrynol Pol 2017; 68 (1): 74-78. Należy cytować wersję pierwotną.

\begin{abstract}
Streszczenie
Hormon anty-müllerowski (AMH) jest glikoproteiną należącą do rodziny transformujących czynników wzrostu beta. Stężenie AMH w surowicy odzwierciedla pulę rosnących pęcherzyków jajnikowych. Zespół policystycznych jajników (PCOS) jest częstą endokrynopatią i wiąże się z rozwojem powikłań, takich jak zaburzenia metaboliczne, niepłodność, choroby układu sercowo-naczyniowego. W pracy przedstawiono rolę AMH w patogenezie PCOS, jego zastosowanie w praktyce klinicznej na podstawie danych z piśmiennictwa. Uważa się, że standaryzacja metody oznaczania AMH w surowicy krwi pozwoli na szersze zastosowanie kliniczne tego peptydu, jako biomarkera zaburzeń funkcji jajnika. (Endokrynol Pol 2017; 68 (1): 74-78)
\end{abstract}

Słowa kluczowe: AMH; PCOS; policystyczna budowa jajnika; insulinooporność; metody wspomaganego rozrodu

\section{Wstęp}

Hormon anty-müllerowski (AMH, Anti-Müllerian hormon) jest glikoproteiną, należącą do rodziny transformujących czynników wzrostu beta (TGF $\beta$, transforming growth factor beta). W praktyce klinicznej AMH jest uznanym markerem rezerwy jajnikowej. Zespół policystycznych jajników (PCOS, polycystic ovary syndro$m e)$ jest najczęstszą endokrynopatią u kobiet w wieku rozrodczym, występującą z częstością sięgającą 6-10\% według kryteriów U.S. National Institutes of Health (NIH) oraz 20\% według kryteriów rotterdamskich [1]. W PCOS stężenie AMH w surowicy krwi jest podwyższone i koreluje z liczbą antralnych pęcherzyków jajnikowych (AFC, antral follicle count) o średnicy 2-6 mm, stwierdzanych w badaniu ultrasonograficznym jajników sondą przezpochwową (USG) [2,3]. W niektórych badaniach wykazano, że AMH jest bardziej specyficznym i czulszym markerem rezerwy jajnikowej niż AFC w badaniu USG [4]. Ponadto zaobserwowano, że stopień nasilenia hiperandrogenizmu oraz występowanie zaburzeń miesiączkowania w PCOS koreluje ze stężeniem AMH w surowicy krwi [5].

\section{AMH - fizjologia}

U płodu męskiego AMH jest produkowany w komórkach Sertoliego rozwijających się jąder. Poprzez aktywację receptora typu II (AMHR-II) powoduje regresję przewodów przyśródnerczowych. AMH odgrywa istotną rolę w procesie różnicowania jąder podczas życia płodowego i jego działanie utrzymuje się aż do okresu dojrzewania [6]. Sekrecja AMH u kobiet rozpoczyna się od 36. tygodnia ciąży i trwa aż do menopauzy. U płodu żeńskiego, w wyniku braku AMH we wczesnym okresie rozwoju embrionalnego, z przewodów Müllera rozwijają się jajowody, macica i 2/3 górne pochwy [7].

Hormon anty-müllerowski produkowany jest w komórkach ziarnistych pęcherzyków wzrastających pre-antralnych i antralnych $\mathrm{w}$ fazie gonadotropowo-niezależnej. Stężenie AMH w surowicy krwi jest odzwierciedleniem ilości AMH produkowanego w pęcherzykach, które są bogato unaczynione [8]. Hormon anty-müllerowski reguluje wzrost pęcherzyków jajnikowych, mając wpływ na rekrutację wzrostu z puli pęcherzyków zawiązkowych i hamując ich wrażliwość na hormon folikulotropowy (FSH) [9]. W cyklu fizjologicznym wzrost stężenia FSH w pierwszych dniach cyklu rekrutuje pęcherzyki antralne do wzrostu w fazie zależnej od gonadotropin. Wejście pęcherzyków w fazę zależną od FSH powoduje hamowanie syntezy AMH i jego stężenie w płynie pęcherzykowym maleje. Z puli zrekrutowanych pęcherzyków, jeden zostaje wyselekcjonowany i owuluje, a pozostałe ulegają atrezji. Proces ten jest zależny od indywidualnej wrażliwości pęcherzyków na FSH. Ekspresję AMH w komórkach ziarnistych, zależnie od stadium rozwoju pęcherzyków, regulują czynniki wydzielane przez komórkę jajową 
$[10,11]$. W fazie okołoowulacyjnej w pęcherzyku, ekspresja AMH zachowana jest w komórkach wzgórka jajonośnego. Dodatkowo wzrastająca sekrecja estrogenów i FSH zwrotnie hamują działanie AMH [12].

Gnoth i wsp., wykorzystując badanie USG jajników o wysokiej rozdzielczości, potwierdzili, że ilość AMH maleje w okresie okołoowulacyjnym wraz ze wzrostem średnicy pęcherzyka do $7 \mathrm{~mm}$ [13]. W dotychczasowych badaniach odnotowano ujemną korelację między stężeniem $\mathrm{AMH}$ a stężeniem estradiolu i ekspresją aromatazy CYP19a1 w płynie pęcherzykowym [14, 15]. W badaniach na zwierzętach, u myszy ze znokautowanym genem $A M H$, pęcherzyki pierwotne są stale rekrutowane, co w konsekwencji wyczerpuje rezerwę jajników i funkcja jajnika wygasa [16]. Przedstawione dane potwierdzają, że AMH odgrywa istotną rolę w rekrutacji pęcherzyków jajnikowych oraz regulacji ich wrażliwości na FSH.

\section{Implikacje kliniczne}

W trakcie życia kobiety szczyt wydzielania $\mathrm{AMH}$ występuje po urodzeniu oraz około 25. roku życia, po czym stopniowo maleje do 50.-51. roku życia, gdy jest już praktycznie nieoznaczalny [17]. Dodatnią korelację między AMH a AFC dostrzeżono w wielu badaniach, a zmienność liczby antralnych pęcherzyków jajnikowych wpływa na stężenia AMH w surowicy krwi [18-21]. Zwrócono również uwagę, że występują różnice w AMH zależne od pochodzenia etnicznego. U kobiet pochodzenia afro-amerykańskiego i hiszpańskiego obserwowano niższe wartości w porównaniu z kobietami rasy kaukaskiej [22, 23]. W cyklu stężenie AMH w surowicy krwi jest stałe, niezależnie od fazy [24]. Ciąża oraz stosowanie doustnej antykoncepcji przyczyniają się do spadku stężenia AMH w surowicy krwi $[25,26]$.

W praktyce klinicznej AMH jest markerem czynnościowej rezerwy jajnikowej i dobrze koreluje z odpowiedzią jajników na stymulację mnogiego jajeczkowania [27]. Oznaczanie AMH można wykorzystać do oceny stopnia uszkodzenia jajników po terapii gonadotoksycznej oraz po leczeniu operacyjnym [28]. W dotychczasowych publikacjach podkreśla się również znaczenie AMH w prognozowaniu czasu wystąpienia menopauzy. Wykazano, że kobiety z niższym stężeniem AMH odpowiednio do wieku mogą spodziewać się menopauzy wcześniej [29]. Zakres wiekowy, w którym prawdopodobnie wystąpi menopauza, może być wyliczony na podstawie wieku oraz stężenia AMH [30]. Ponadto, należy podkreślić, że kobiety z cukrzycą typu 1 (T1DM) mają okres przekwitania w młodszym wieku, nawet o 8 lat wcześniej w porównaniu ze swoimi siostrami [31]. Soto i wsp. zaobserwowali niższe stężenia AMH w czwartej dekadzie życia u kobiet z T1DM, co sugeruje przedwczesne wygasanie czynności jajników i redukcję rezerwy jajnikowej [32]. Nie można jednak wykluczyć tła genetycznego przedwczesnej menopauzy u kobiet z T1DM [33].

\section{AMH w PCOS}

Zespół policystycznych jajników charakteryzują trzy główne objawy - obecność zaburzeń miesiączkowania o typie oligomenorrhea/amenorrhea (OM), kliniczne lub biochemiczne cechy hiperandrogenizmu (HA) (hirsutyzm, trądzik, łysienie) oraz obraz policystycznych jajników w badaniu ultrasonograficznym (PCOM). Według kryteriów rotterdamskich wyróżnia się cztery fenotypy PCOS - I fenotyp klasyczny spełniający wszystkie trzy kryteria, II fenotyp - z HA i OM, III fenotyp - z HA i PCOM, IV fenotyp - z OM i PCOM [34]. W patogenezie zespołu odgrywa rolę wiele czynników zarówno genetycznych, jak i środowiskowych [35]. Kobiety z PCOS stanowią grupę zwiększonego ryzyka otyłości, insulinooporności, zespołu metabolicznego, cukrzycy typu 2, niepłodności, chorób układu sercowo-naczyniowego [1, 36].

Stężenie AMH w surowicy krwi jest wyższe u kobiet z PCOS i odzwierciedla pulę rosnących pęcherzyków obecnych w policystycznym jajniku. Wykazano, że $\mathrm{u}$ kobiet z PCOS i zaburzeniami owulacji, komórki ziarniste produkują 75-krotnie więcej AMH, a u kobiet bez zaburzeń miesiączkowania 20-krotnie więcej AMH, w porównaniu z kobietami zdrowymi $[37,38]$. Stężenia AMH w płynie pęcherzykowym u kobiet z PCOS są również wyższe [39]. Przyczyny tak wysokiego stężenia $\mathrm{AMH}$ u kobiet $\mathrm{z}$ PCOS nie są dotychczas dobrze poznane. Istotną rolę może odgrywać podwyższone stężenie androgenów w płynie pęcherzykowym. Wewnętrzny defekt w komórkach tekalnych jajnika pacjentek z PCOS powoduje nadmierną syntezę androgenów [40]. Hiperandrogenemia stymuluje wzrost preantralnych i antralnych pęcherzyków jajnikowych [41]. Wyniki badań Cassar i wsp. wskazują, że testosteron wpływa niezależnie na stężenie AMH w surowicy w PCOS [42]. Dodatkowo, LH może zmniejszać ekspresję AMHRII u kobiet zdrowych, jak też u kobiet z PCOS regularnie miesiączkujących, czego nie obserwowano u kobiet z PCOS z zaburzeniami miesiączkowania [43]. Dane te wskazują na istotną rolę AMH w zaburzeniach owulacji w PCOS.

\section{AMH a fenotypy PCOS}

Stężenie AMH odzwierciedla stopień nasilenia zaburzeń w PCOS - najwyższe stężenia AMH obserwuje się u kobiet z fenotypem klasycznym [5, 44]. Dla potwierdzenia tej tezy Tal i wsp. wykazali, że aż 97\% kobiet z AMH > $10 \mathrm{ng} / \mathrm{ml}$ miało objawy PCOS, a stę- 
żenie AMH korelowało ze stężeniem LH, testosteronu, siarczanu dihydroepiandrosteronu i było istotnym czynnikiem predykcyjnym występowania zaburzeń miesiączkowania [45]. Zwrócono uwagę, że stosunek AMH do AFC (AMH/AFC) ma większe znaczenie prognostyczne w prognozowaniu występowania zaburzeń miesiączkowania niż samo AMH. Wykazano wyższy AMH/AFC u kobiet z zaburzeniami miesiączkowania w porównaniu z kobietami regularnie miesiączkującymi w PCOS [46].

\section{AMH - zwiqzek $z$ otyłościq i insulinoopornościq $w$ PCOS}

Dotychczasowe badania oceniające związek AMH z otyłością są sprzeczne. Olszanecka-Glinianowicz i wsp. obserwowali niższe stężenia AMH u kobiet otyłych z PCOS niż u kobiet z prawidłową masą ciała i PCOS [47]. W przeciwieństwie do tych danych Cassar i wsp. nie stwierdzili różnic w AMH pomiędzy grupami różniącymi się BMI z PCOS [42]. W przeprowadzonych badaniach wykazano, że insulinooporność (IR) towarzysząca otyłości, upośledza funkcję komórek ziarnistych i zmniejsza produkcję AMH [48]. Ponadto, zahamowanie wydzielania gonadotropin, szczególnie LH, prowadzi do braku postępu rozwoju pęcherzyka i wzrostu AMH [49]. Biorąc pod uwagę, że u większości kobiet z PCOS występuje insulinooporność, zależność AMH od IR jest przedmiotem wielu badań. Wykazano dodatnią, ujemną, bądź brak korelacji między stężeniem AMH w surowicy a pośrednimi wskaźnikami IR $[37,47,50]$. Cassar i wsp., w badaniu z wykorzystaniem klamry euglikemiczo-hiperinsulinemicznej do oceny wrażliwości tkanek obwodowych na insulinę, nie potwierdzili bezpośredniego związku pomiędzy stężeniem AMH w surowicy a współczynnikiem insulinowrażliwości, ale odnotowano związek pomiędzy IR a stężeniem androgenów, co może pośrednio wskazywać na udział w regulacji wydzielania $\mathrm{AMH}[42]$.

\section{AMH w diagnostyce PCOS}

Zaproponowano, aby oznaczenie stężenia AMH wykorzystać w diagnostyce zespołu PCOS jako kryterium zastępujące dotychczasowo obowiązujące kryterium PCOMi przy stężeniu AMH $>35 \mathrm{pmol} / \mathrm{l}(\mathrm{lub}>5 \mathrm{ng} / \mathrm{ml})$ rozpoznać zespół PCOS [4]. Ponadto, stosowanie aparatów ultrasonograficznych o wysokiej rozdzielczości umożliwia dokładniejszą ocenę puli pęcherzyków jajnikowych. Skłania to do zmiany kryterium liczby pęcherzyków jajnikowych z 12 (wg kryteriów rotterdamskich z 2003 r.) do 19 bądź 25 [4, 51]. Lauritsen i wsp. uważają, że przy stężeniu AMH w surowicy krwi $>35$ pmol// lub liczbie pęcherzyków jajnika przekraczającej 19, częstość występowania PCOS była niższa odpowiednio 8,5\% i 6,3\% w porównaniu z częstością $16,6 \%$ przy kryteriach rotterdamskich [52]. Warto zwrócić uwagę, że współwystępowanie OM i/lub HA z podwyższonym stężeniem AMH pozwala na diagnozę PCOS z czułością $83 \%$ i specyficznością 100\%, według kryteriów rotterdamskich [53].

Do oznaczenia stężenia AMH w surowicy wykorzystywane były różne metody, co sprawia, że uzyskane wyniki nie zawsze mogą być ze sobą porównywane. Do 2010 roku zastosowanie miały zestawy komercyjne ELISA I generacji, pochodzące $\mathrm{z}$ dwóch laboratoriów: Diagnostic System Laboratories (DSL) i Immunotech (IOT). Następnie, te metody zostały zastąpione metodą ELISA II generacji przygotowaną przez laboratorium Beckman Coulter [54]. W 2013 roku wprowadzono modyfikację do oznaczeń II generacji, która polegała na dodatkowym rozcieńczeniu próbki, co dawało bardziej wiarygodne oznaczenia stężenia AMH w badanym materiale [55]. Obecnie, dostępne są w pełni zautomatyzowane metody do oznaczenia stężeń AMH w materiale biologicznym (Elecsys AMH, Roche oraz Acess, AMH, Beckam Coulter) [56]. Warto podkreślić, że dostępne są również nowe, bardziej czułe zestawy wykorzystujące metodę ELISA (picoAMH ELISA, AnshLabs), które pozwalają na oznaczanie niższych stężeń AMH. Może to mieć znaczenie w diagnostyce, $\mathrm{u}$ kobiet $\mathrm{z}$ niską rezerwą jajnikową [57]. Jak dotychczas nie ustalono wartości granicznej dla stężenia AMH. Androgen Excess Society Task Force w chwili obecnej nie zaleca stosowania AMH w kryteriach rozpoznawania PCOS, do czasu dokonania standaryzacji oznaczeń AMH [54].

\section{AMH a metody wspomaganego rozrodu}

Zastosowanie egzogennego FSH w leczeniu niepłodności metodami wspomaganego rozrodu pozwala na uzyskaniu wzrostu wielu pęcherzyków jajnikowych. Nadmierny rozwój pęcherzyków może prowadzić do poważnego powikłania stymulacji — zespółu hiperstymulacji jajników.

Markerami pozwalającymi przewidzieć odpowiedź są pomiary ultrasonograficzne, stężenie FSH, inhibiny, $17-\beta$-estradiolu oraz AMH. Spośród tych markerów stężenie AMH jest najbardziej specyficznym i czułym markerem odpowiedzi jajnika [58]. Seifer i wsp., jako jedni z pierwszych badaczy, opisali, że AMH koreluje z liczbą uzyskanych oocytów u kobiet z niepłodnością [59]. Dotychczasowe badania określają AMH jako czynnik predykcyjny zarówno zwiększonej, jak i zmniejszonej odpowiedzi jajników na stymulację mnogiego jajeczkowania [27, 60]. Nowe techniki ultraczułe oznaczenie AMH w surowicy krwi metodą picoAMH - pozwalają na wykrycie bardzo niskich stężeń AMH [57] 


\section{Podsumowanie}

Hormon anty-müllerowski stanowi obiecujący marker rezerwy funkcjonalnej i funkcji jajników, z szerokim zastosowaniem w praktyce klinicznej. PCOS wiąże się z zaburzeniami płodności, zaburzeniami metabolicznymi, problemami psychologicznymi i jest najczęstszą przyczyną niepłodności wynikajacej z braku owulacji. Hormon anty-müllerowski jest nieocenionym narzędziem w diagnostyce, ocenie funkcji jajnika i odpowiedzi na leczenie, w szczególności u kobiet z PCOS.

\section{Podziękowania}

Dziękujemy Panu Prof. dr hab. Sławomirowi Wołczyńskiemu z Kliniki Rozrodczości i Endokrynologii Ginekologicznej UMB za uwagi i komentarze do niniejszej pracy.

\section{Piśmiennictwo}

1. Fauser BC, Tarlatzis BC, Rebar RW, et al. Consensus on women's health aspects of polycystic ovary syndrome (PCOS): the Amsterdam ESHRE/ ASRM-Sponsored 3rd PCOS Consensus Workshop Group. Fertil Steril. 2012; 97(1): 28-38.e25, doi: 10.1016/j.fertnstert.2011.09.024, indexed in Pubmed: 22153789.

2. Pigny P, Merlen E, Robert Y, et al. Elevated serum level of anti-mullerian hormone in patients with polycystic ovary syndrome: relationship to the ovarian follicle excess and to the follicular arrest. J Clin Endocrinol Metab. 2003; 88(12): 5957-5962, doi: 10.1210/jc.2003-030727, indexed in Pubmed: 14671196.

3. Pigny P, Jonard S, Robert Y, et al. Serum anti-Mullerian hormone as a surrogate for antral follicle count for definition of the polycystic ovary syndrome. J Clin Endocrinol Metab. 2006; 91(3): 941-945, doi: 10.1210/jc.2005-2076, indexed in Pubmed: 16368745.

4. Dewailly D, Gronier H, Poncelet E, et al. Diagnosis of polycystic ovary syndrome (PCOS): revisiting the threshold values of follicle count on ultrasound and of the serum AMH level for the definition of polycystic ovaries. Hum Reprod. 2011; 26(11): 3123-3129, doi: 10.1093/humrep/der297, indexed in Pubmed: 21926054

5. Piouka A, Farmakiotis D, Katsikis I, et al. Anti-Mullerian hormone levels reflect severity of PCOS but are negatively influenced by obesity: relationship with increased luteinizing hormone levels. Am J Physiol Endocrinol Metab. 2009; 296(2): E238-E243, doi: 10.1152/ajpendo.90684.2008, indexed in Pubmed: 18957615.

6. Rey RA, Grinspon RP, Gottlieb S, et al. Male hypogonadism: an extended classification based on a developmental, endocrine physiology-based approach. Andrology. 2013; 1(1): 3-16, doi: 10.1111/i.2047-2927.2012.00008.x, indexed in Pubmed: 23258624

7. La Marca A, Volpe A. Anti-Müllerian hormone (AMH) in female reproduction: is measurement of circulating AMH a useful tool? Clin Endocrinol (Oxf). 2006; 64(6): 603-610, doi: 10.1111/j.1365-2265.2006.02533.x, indexed in Pubmed: $\underline{16712660}$

8. Dewailly D, Andersen CY, Balen A, et al. The physiology and clinical utility of anti-Mullerian hormone in women. Hum Reprod Update. 2014; 20(3): 370-385, doi: $10.1093 / \mathrm{humupd} / \mathrm{dmt} 062$, indexed in Pubmed: 24430863.

9. Pellatt L, Rice S, Dilaver N, et al. Anti-Müllerian hormone reduces follicle sensitivity to follicle-stimulating hormone in human granulosa cells. Fertil Steril. 2011; 96(5): 1246-12451.e1, doi: 10.1016/j.fertnstert.2011.08.015, indexed in Pubmed: 21917251.

10. Andersen CY, Schmidt KT, Kristensen SG, et al. Concentrations of AMH and inhibin-B in relation to follicular diameter in normal human small antral follicles. Hum Reprod. 2010; 25(5): 1282-1287, doi: 10.1093/humrep/deq019, indexed in Pubmed: 20228388.

11. Peluso C, Fonseca FLA, Rodart IF, et al. AMH: An ovarian reserve biomarker in assisted reproduction. Clin Chim Acta. 2014; 437: 175-182, doi: 10.1016/j. cca.2014.07.029, indexed in Pubmed: 25086280.

12. Grynberg M, Pierre A, Rey R, et al. Differential regulation of ovarian anti-müllerian hormone $(\mathrm{AMH})$ by estradiol through $\alpha$ - and $\beta$-estrogen receptors. J Clin Endocrinol Metab. 2012; 97(9): E1649-E1657, doi: 10.1210/jc.2011-3133, indexed in Pubmed: 22689696.

13. Gnoth C, Roos J, Broomhead D, et al. Antimüllerian hormone levels and numbers and sizes of antral follicles in regularly menstruating women of reproducti- ve age referenced to true ovulation day. Fertil Steril. 2015; 104(6): 1535-15343. e1, doi: 10.1016/j.fertnstert.2015.08.027, indexed in Pubmed: 26384163 .

14. Nielsen ME, Rasmussen IA, Kristensen SG, et al. In human granulosa cells from small antral follicles, androgen receptor mRNA and androgen levels in follicular fluid correlate with FSH receptor mRNA. Mol Hum Reprod. 2011; 17(1): 63-70, doi: 10.1093/molehr/gaq073, indexed in Pubmed: 20843821.

15. Andersen CY, Byskov AG. Estradiol and regulation of anti-Müllerian hormone, inhibin-A, and inhibin-B secretion: analysis of small antral and preovulatory human follicles' fluid. J Clin Endocrinol Metab. 2006; 91(10): 4064-4069, doi: $10.1210 /$ jc. 2006-1066, indexed in Pubmed: 16895952.

16. Visser JA, Durlinger ALL, Peters IJJ, et al. Increased oocyte degeneration and follicular atresia during the estrous cycle in anti-Müllerian hormone null mice. Endocrinology. 2007; 148(5): 2301-2308, doi: 10.1210/en.2006-1265, indexed in Pubmed: 17255205.

17. Kelsey TW, Wright P, Nelson SM, et al. A validated model of serum anti-müllerian hormone from conception to menopause. PLoS One. 2011; 6(7): e22024, doi: 10.1371/iournal.pone.0022024, indexed in Pubmed: 21789206.

18. La Marca A, Spada E, Sighinolfi G, et al. Age-specific nomogram for the decline in antral follicle count throughout the reproductive period. Fertil Steril. 2011; 95(2): 684-688, doi: 10.1016/i.fertnstert.2010.07.1069, indexed in Pubmed: 20797717.

19. Fanchin R, Schonäuer LM, Righini C, et al. Serum anti-Müllerian hormone is more strongly related to ovarian follicular status than serum inhibin B, estradiol, FSH and LH on day 3. Hum Reprod. 2003; 18(2): 323-327, indexed in Pubmed: 12571168.

20. Broekmans FJM, de Ziegler D, Howles CM, et al. The antral follicle count: practical recommendations for better standardization. Fertil Steril. 2010; 94(3): 1044-1051, doi: 10.1016/i.fertnstert.2009.04.040, indexed in Pubmed: 19589513 .

21. Jeppesen JV, Anderson RA, Kelsey TW, et al. Which follicles make the most anti-Mullerian hormone in humans? Evidence for an abrupt decline in AMH production at the time of follicle selection. Mol Hum Reprod. 2013; 19(8): 519-527, doi: 10.1093/molehr/gat024, indexed in Pubmed: 23562944.

22. Seifer DB, Golub ET, Lambert-Messerlian G, et al. Variations in serum müllerian inhibiting substance between white, black, and Hispanic women. Fertil Steril. 2009; 92(5): 1674-1678, doi: 10.1016/j.fertnstert.2008.08.110, indexed in Pubmed: 18930217.

23. Schuh-Huerta SM, Johnson NA, Rosen MP, et al. Genetic variants and environmental factors associated with hormonal markers of ovarian reserve in Caucasian and African American women. Hum Reprod. 2012; 27(2): 594-608, doi: 10.1093/humrep/der391, indexed in Pubmed: 22116950.

24. Lambert-Messerlian G, Plante B, Eklund EE, et al. Levels of antimüllerian hormone in serum during the normal menstrual cycle. Fertil Steril. 2016; 105(1): 208-213.e1, doi: 10.1016/j.fertnstert.2015.09.033, indexed in Pubmed: 26477497

25. Bentzen JG, Forman JL, Pinborg A, et al. Ovarian reserve parameters: a comparison between users and non-users of hormonal contraception. Reprod Biomed Online. 2012; 25(6): 612-619, doi: 10.1016/j. rbmo.2012.09.001, indexed in Pubmed: 23069740.

26. Nelson SM, Stewart F, Fleming R, et al. Longitudinal assessment of antimüllerian hormone during pregnancy-relationship with maternal adiposity, insulin, and adiponectin. Fertil Steril. 2010; 93(4): 1356-1358, doi: 10.1016/j.fertnstert.2009.07.1676, indexed in Pubmed: 19800062.

27. Broer SL, van Disseldorp J, Broeze KA, et al. IMPORT study group. Added value of ovarian reserve testing on patient characteristics in the prediction of ovarian response and ongoing pregnancy: an individual patient data approach. Hum Reprod Update. 2013; 19(1): 26-36, doi: $\underline{10.1093 / h u m u p d / d m s 041}$, indexed in Pubmed: 23188168.

28. Partridge AH, Ruddy KJ, Gelber S, et al. Ovarian reserve in women who remain premenopausal after chemotherapy for early stage breast cancer Fertil Steril. 2010; 94(2): 638-644, doi: 10.1016/j.fertnstert.2009.03.045, indexed in Pubmed: 19409543.

29. Tehrani FR, Solaymani-Dodaran M, Azizi F. A single test of antimullerian hormone in late reproductive-aged women is a good predictor of menopause. Menopause. 2009; 16(4): 797-802, doi: 10.1097/gme.0b013e318193e95d, indexed in Pubmed: 19225427.

30. Broer SL, Eijkemans MJC, Scheffer GJ, et al. Anti-mullerian hormone predicts menopause: a long-term follow-up study in normoovulatory women. J Clin Endocrinol Metab. 2011; 96(8): 2532-2539, doi: 10.1210/ jc.2010-2776, indexed in Pubmed: 21613357.

31. Dorman JS, Steenkiste AR, Foley TP, et al. Familial Autoimmune and Diabetes (FAD) Study. Menopause in type 1 diabetic women: is it premature? Diabetes. 2001; 50(8): 1857-1862, indexed in Pubmed: 11473049.

32. Soto N, Iñiguez G, López P, et al. Anti-Mullerian hormone and inhibin $B$ levels as markers of premature ovarian aging and transition to menopause in type 1 diabetes mellitus. Hum Reprod. 2009; 24(11): 2838-2844, doi: 10.1093/humrep/dep276, indexed in Pubmed: 19643804.

33. Voorhuis M, Onland-Moret NC, van der Schouw YT, et al. Human studies on genetics of the age at natural menopause: a systematic review. Hum Reprod Update. 2010; 16(4): 364-377, doi: 10.1093/humupd/dmp055, indexed in Pubmed: 20071357. 
34. Rotterdam ESHRE/ASRM-Sponsored PCOS Consensus Workshop Group, Rotterdam ESHRE/ASRM-Sponsored PCOS consensus workshop group. Revised 2003 consensus on diagnostic criteria and long-term health risks related to polycystic ovary syndrome (PCOS). Hum Reprod. 2004; 19(1): 41-47, indexed in Pubmed: 14688154.

35. McAllister JM, Legro RS, Modi BP, et al. Functional genomics of PCOS: from GWAS to molecular mechanisms. Trends Endocrinol Metab. 2015; 26(3): 118-124, doi: 10.1016/j.tem.2014.12.004, indexed in Pubmed: 25600292.

36. Foltyn W, Strzelczyk J, Marek B, et al. Selected markers of endothelia dysfunction in women with polycystic ovary syndrome. Endokrynol Pol. 2011; 62(3): 243-248, indexed in Pubmed: 21717407.

37. Park AS, Lawson MA, Chuan SS, et al. Serum anti-mullerian hormone concentrations are elevated in oligomenorrheic girls without evidence of hyperandrogenism. J Clin Endocrinol Metab. 2010; 95(4): 1786-1792, doi: 10.1210/jc.2009-2106, indexed in Pubmed: 20150576.

38. Pellatt L, Hanna L, Brincat M, et al. Granulosa cell production of anti-Müllerian hormone is increased in polycystic ovaries. J Clin Endocrinol Metab. 2007; 92(1): 240-245, doi: 10.1210/jc.2006-1582, indexed in Pubmed: 17062765.

39. Das M, Gillott DJ, Saridogan E, et al. Anti-Mullerian hormone is increased in follicular fluid from unstimulated ovaries in women with polycystic ovary syndrome. Hum Reprod. 2008; 23(9): 2122-2126, doi: 10.1093/ humrep/den185, indexed in Pubmed: 18550512.

40. Gilling-Smith C, Willis DS, Beard RW, et al. Hypersecretion of androstenedione by isolated thecal cells from polycystic ovaries. J Clin Endocrinol Metab. 1994; 79(4): 1158-1165, doi: 10.1210/icem.79.4.7962289, indexed in Pubmed: 7962289.

41. Diamanti-Kandarakis E, Christakou CD, Kandaraki E, et al. Polycystic ovarian syndrome: pathophysiology, molecular aspects and clinica implications. Expert Rev Mol Med. 2008; 10(2): e3-212, doi: 10.1017 S1462399408000598, indexed in Pubmed: 18230193.

42. Cassar S, Teede HJ, Moran LJ, et al. Polycystic ovary syndrome and anti-Müllerian hormone: role of insulin resistance, androgens, obesity and gonadotrophins. Clin Endocrinol (Oxf). 2014; 81(6): 899-906, doi: 10.1111 cen.12557, indexed in Pubmed: 25040369.

43. Pierre A, Peigné M, Grynberg M, et al. Loss of LH-induced down-regulation of anti-Müllerian hormone receptor expression may contribute to anovulation in women with polycystic ovary syndrome. Hum Reprod. 2013; 28(3): 762-769, doi: 10.1093/humrep/des460, indexed in Pubmed: 23321213.

44. Sahmay S, Atakul N, Oncul M, et al. Serum anti-Mullerian hormone levels in the main phenotypes of polycystic ovary syndrome. Eur J Obstet Gynecol Reprod Biol. 2013; 170(1): 157-161, doi: 10.1016/j.ejogrb.2013.05.019, indexed in Pubmed: 23806449.

45. Tal R, Seifer DB, Khanimov M, et al. Characterization of women with elevated antimüllerian hormone levels $(\mathrm{AMH})$ : correlation of $\mathrm{AMH}$ with polycystic ovarian syndrome phenotypes and assisted reproductive technology outcomes. Am J Obstet Gynecol. 2014; 211(1): 59.e1-59.e8, doi: 10.1016/j.ajog.2014.02.026, indexed in Pubmed: 24593938.

46. Alebić MŠ, Stojanović N, Duhamel A, et al. The phenotypic diversity in per-follicle anti-Müllerian hormone production in polycystic ovary syndrome. Hum Reprod. 2015; 30(8): 1927-1933, doi: 10.1093/humrep/ dev131, indexed in Pubmed: 26048913.

47. Olszanecka-Glinianowicz M, Madej P, Owczarek A, et al. Circulating anti-Müllerian hormone levels in relation to nutritional status and selected adipokines levels in polycystic ovary syndrome. Clin Endocrinol (Oxf) 2015; 83(1): 98-104, doi: 10.1111/cen.12687, indexed in Pubmed: 25440474.
48. Chen MJ, Yang WS, Chen CL, et al. The relationship between anti-Mullerian hormone, androgen and insulin resistance on the number of antral follicles in women with polycystic ovary syndrome. Hum Reprod. 2008; 23(4): 952-957, doi: 10.1093/humrep/den015, indexed in Pubmed: 18256110.

49. Grossman MP, Nakajima ST, Fallat ME, et al. Müllerian-inhibiting substance inhibits cytochrome $\mathrm{P} 450$ aromatase activity in human granulosa lutein cell culture. Fertil Steril. 2008; 89(5 Suppl): 1364-1370, doi: 10.1016/j. fertnstert.2007.03.066, indexed in Pubmed: 17517397.

50. Skałba P, Cygal A, Madej P, et al. Is the plasma anti-Müllerian hormone $(\mathrm{AMH})$ level associated with body weight and metabolic, and hormonal disturbances in women with and without polycystic ovary syndrome? Eur J Obstet Gynecol Reprod Biol. 2011; 158(2): 254-259, doi: 10.1016/i. ejogrb.2011.06.006, indexed in Pubmed: 21752527.

51. Lujan ME, Jarrett BY, Brooks ED, et al. Updated ultrasound criteria for polycystic ovary syndrome: reliable thresholds for elevated follicle population and ovarian volume. Hum Reprod. 2013; 28(5): 1361-1368, doi: 10.1093/humrep/det062, indexed in Pubmed: 23503943.

52. Lauritsen MP, Bentzen JG, Pinborg A, et al. The prevalence of polycystic ovary syndrome in a normal population according to the Rotterdam criteria versus revised criteria including anti-Mullerian hormone. Hum Reprod. 2014; 29(4): 791-801, doi: 10.1093/humrep/det469, indexed in Pubmed: 24435776.

53. Sahmay S, Aydin Y, Oncul M, et al. Diagnosis of Polycystic Ovary Syndrome: AMH in combination with clinical symptoms. J Assist Reprod Genet. 2014; 31(2): 213-220, doi: 10.1007/s10815-013-0149-0, indexed in Pubmed: 24343036

54. Dewailly D, Lujan ME, Carmina E, et al. Definition and significance of polycystic ovarian morphology: a task force report from the Androgen Excess and Polycystic Ovary Syndrome Society. Hum Reprod Update. 2014; 20(3): 334-352, doi: 10.1093/humupd/dmt061, indexed in Pubmed: 24345633

55. Craciunas L, Roberts SA, Yates AP, et al. Modification of the Beckman-Coulter second-generation enzyme-linked immunosorbent assay protocol improves the reliability of serum antimüllerian hormone measurement. Fertil Steril. 2015; 103(2): 554-59.e1, doi: 10.1016/j.fertnstert.2014.10.052, indexed in Pubmed: 25487749.

56. Nelson SM, Pastuszek E, Kloss G, et al. Two new automated, compared with two enzyme-linked immunosorbent, antimüllerian hormone assays. Fertil Steril. 2015; 104(4): 1016-1021.e6, doi: 10.1016/j.fertnstert.2015.06.024, indexed in Pubmed: 26183313.

57. Burks HR, Ross L, Opper N, et al. Can highly sensitive antimüllerian hormone testing predict failed response to ovarian stimulation? Fertil Steril. 2015; 104(3): 643-648, doi: 10.1016/j.fertnstert.2015.06.018, indexed in Pubmed: 26158904.

58. Broekmans FJ, Kwee J, Hendriks DJ, et al. A systematic review of tests predicting ovarian reserve and IVF outcome. Hum Reprod Update. 2006; 12(6): 685-718, doi: 10.1093/humupd/dml034, indexed in Pubmed: 16891297.

59. Seifer DB, MacLaughlin DT, Christian BP, et al. Early follicular serum müllerian-inhibiting substance levels are associated with ovarian response during assisted reproductive technology cycles. Fertil Steril. 2002; 77(3): 468-471, indexed in Pubmed: 11872196.

60. Broer SL, Dólleman M, van Disseldorp J et al. Prediction of an excessive response in in vitro fertilization from patient characteristics and ovarian reserve tests and comparison in subgroups: an individual patient data meta-analysis. Fertil Steril 2013; 100: 420-429.e7. doi: 10.1016/j. fertnstert.2013.04.024 